\title{
Investigation of Mechanical Properties of Boronized 2365 Steel by Pulsed Plasma-Electrolysis Technique
}

\author{
Orhan Akyüz ${ }^{{ }^{*}}$ and Zekai Tek ${ }^{2}$ \\ 1. Department of Materials Science and Engineering, Faculty of Science and Arts, İmir Katip Celebi University, İmir 35000, \\ Turkey \\ 2. Department of Physics, Faculty of Science and Arts, Celal Bayar University, Manisa 45040, Turkey
}

\begin{abstract}
In this study, pulsed plasma electrolysis technique has been used, in order to improve the surface hardness and wear resistance of the 2365 substrates. Polished-2365 samples were boronized by plasma electrolysis by using borax aqueous solutions at two different concentrations and two different test durations. The mechanical properties of both the modified and unmodified samples has been carried out by means of the micro-hardness, wear resistance and friction coefficient measurements. The modified samples were characterized by SEM (scanning electron microscope) and EDX (energy-dispersive X-ray spectroscopy).
\end{abstract}

Key words: Pulsed plasma electrolysis, 2365 steel, boronizing, surface coating, wear behavior.

\section{Introduction}

Material surface modification has a role in controlling the material life, which is exposed to environmental effects and against wearing and corrosion. Various surface techniques have been started to used commonly in increasing materials' working life and the economic efficiency progressively [1]. Every year, lots of economies have great losses because of the wearing and corrosion of some machine parts and patterns in various branches of industry. Wearing and corrosion components generally exist on the surface of the material [2]. Due to their high tensile strength, excellent plastic and tough characteristics, steels are easy to work,. However, wear resistance, surface hardness and corrosion resistance of steel is much lower than that of ceramic materials [3, 4]. For this reason, various works are done in order to strengthen steel surfaces. In recent years, comprehensive researches on steel surface procedures have been performed to increase

Corresponding author: Orhan Akyüz, Ph.D. student, research fields: surface coatings, tribological properties, thermal spray and metals. E-mail: Orhan.akyuz@deu.edu.tr. the wear resistance, the hardness and the chemical resistance $[5,6]$.

Plasma electrolysis is a kind of electrochemical process. Plasma is created by DC (direct current) or DC pulsed glow discharges between an electrode and the surface of the electrolyte [7]. This method is including PEO (plasma electrolytic anodic oxidation) and PES (plasma electrolytic saturation). The main differences between traditional electrolysis and plasma electrolysis is the possibility of a workpiece heating to a high temperature. Actually, the applied electrode potential in all the electrolytic plasma process is considerably higher than that of the traditional processes $[3,8]$. Some of the suitable surface improvement techniques in a plasma environment for steel are carburation, nitriding and boronizing $[5,9]$.

Boronizing is an important method for improving surface hardness and it is generally used by engineers. In this method, borid layers are created on the surface pattern with the help of boron diffusion. Then, it is observed if $\mathrm{FeB}$ and $\mathrm{Fe}_{2} \mathrm{~B}$ phases are happening on the pattern or not $[10,11]$. Borid layer increases the 
surface hardness (1300-2100 HV) and wear resistance, thus increases the life of the pattern 3 to 10 times. Boronizing can be done through various methods. These methods are: power pack boronizing, molten salt boronizing, gas boronizing, fluidized bed boronizing, electrochemical boronizing etc. Plasma boronizing and electrochemical boronizing are the ones that supply desired borid phases in a short time. Since the borid diffusion speed is quicker than the traditional boronizing speed, formation of a thicker borid layer is expected. In previous study, M.A. Béjar and his friends investigated surface hardening of steel by plasma-electrolysis boronizing [12, 13].

In this study, mechanical and structural behavior of 2365 steel was investigated by using pulsed plasma-electrolysis boronizing technique. The aim of this study is to investigate the coating thickness, mechanical properties such as wear resistance, microhardness and friction coefficient of this iron boron coating. The effects of the concentration of borax $\left(\mathrm{Na}_{2} \mathrm{~B}_{4} \mathrm{O}_{7}\right)$ and treatment time were evaluated.
We hoped that the iron boron coating by plasma electrolysis method would be beneficial for improving the wear resistance and microhardness of steel substrates.

\section{Experiments}

Steel samples of $15 \mathrm{~mm}$ in diameter and $5 \mathrm{~mm}$ thick were prepared. Before electrolysis, samples were brushed with $800,1200,1500$ emeries respectively and polished with diamond suspensions. These steel samples were boronized in two different concentrations and two different test durations. Samples were used as electrodes and a stainless steel electrode with a wider surface area was positioned in a distance of $18 \mathrm{~mm} .10 \%-15 \%$ borax was used as the electrolyte composition and 5\%-7\% $\mathrm{NaOH}$ was added to the solution in order to increase conductivity. Steel was positioned in cathode side as electrode and the boron was made diffuse to their surface through the solution. Alloy composition rates of the used 2365 steel are given in Table 1.

Table 1 Composition of 2365 steel alloy by weight [14].

\begin{tabular}{lllllllll}
\hline & $\mathbf{C}$ & $\mathbf{S i}$ & $\mathbf{M n}$ & $\mathbf{P}$ & $\mathbf{S}$ & $\mathbf{C r}$ & $\mathbf{M o}$ & $\mathbf{V}$ \\
\hline Typical analysis & 0.30 & 0.30 & 0.30 & 0.025 & 0.003 & 3.00 & 2.80 & 0.60 \\
Chemical composition & $0.28-0.35$ & $0.10-0.40$ & $0.15-0.45$ & $\leq 0.030$ & $\leq 0.020$ & $2.70-3.20$ & $2.50-3.00$ & $0.40-0.70$ \\
\hline
\end{tabular}

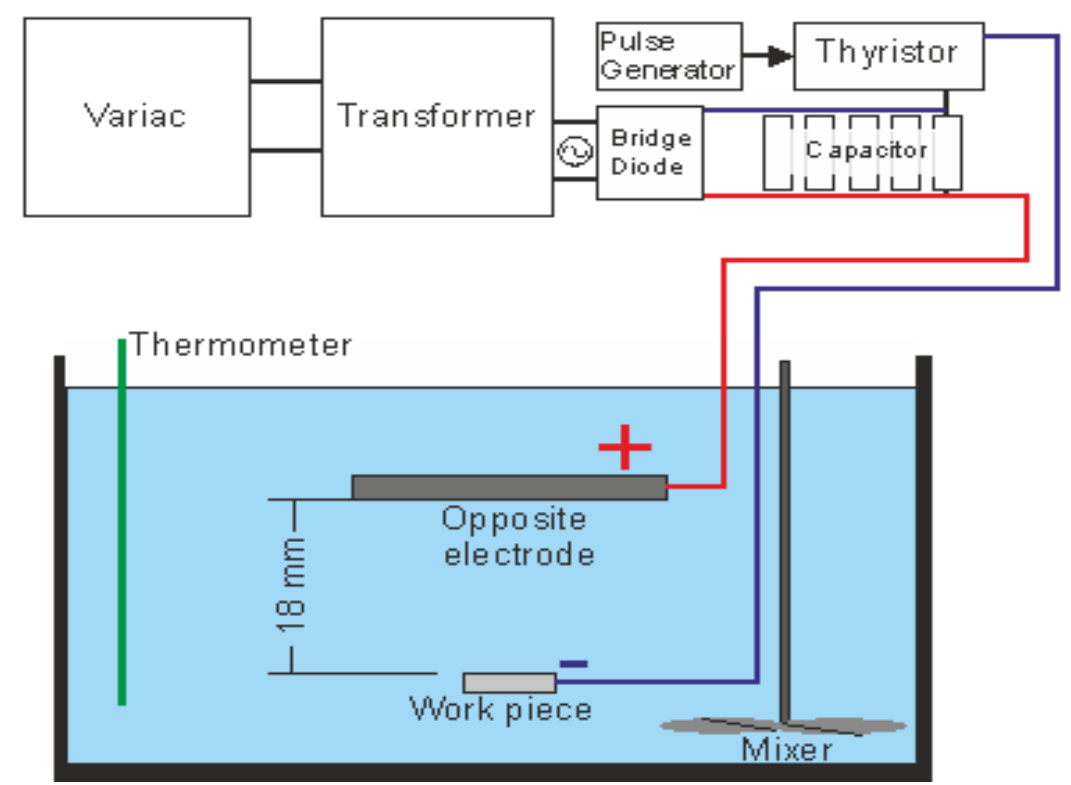

Fig. 1 Schematic diagram of pulsed plasma-electrolysis setup. 
Pulsed plasma electrolysis experimental setup is shown in Fig. 1 schematically. In every minute, 35 pulse of 1050 volts charges coming from the system, comprised of $300 \mu \mathrm{F}$ condenser, were applied to the material. In these conditions, the materials were boronized for $4 \mathrm{~h}$ (short process) and $8 \mathrm{~h}$ (long process). Besides different boronizing periods, the effects of 2 different concentrations, i.e. $10 \% \mathrm{Na}_{2} \mathrm{~B}_{4} \mathrm{O}_{7}$ (borax) $5 \% \mathrm{NaOH}$ and $15 \% \mathrm{Na}_{2} \mathrm{~B}_{4} \mathrm{O}_{7} 7 \% \mathrm{NaOH}$ electrolysis solutions, on boronizing were examined. Electrolyte temperature was increased to maximum $50{ }^{\circ} \mathrm{C}$ for all process durations.

Codes, electrolyte concentrations and application processes of the samples are given in Table 2. For the structural characterization of boronized surface, which was formed using pulsed plasma-electrolysis technique, SEM (scanning electron microscope) and EDX (energy-dispersive X-ray spectroscopy) techniques were used. For the mechanical
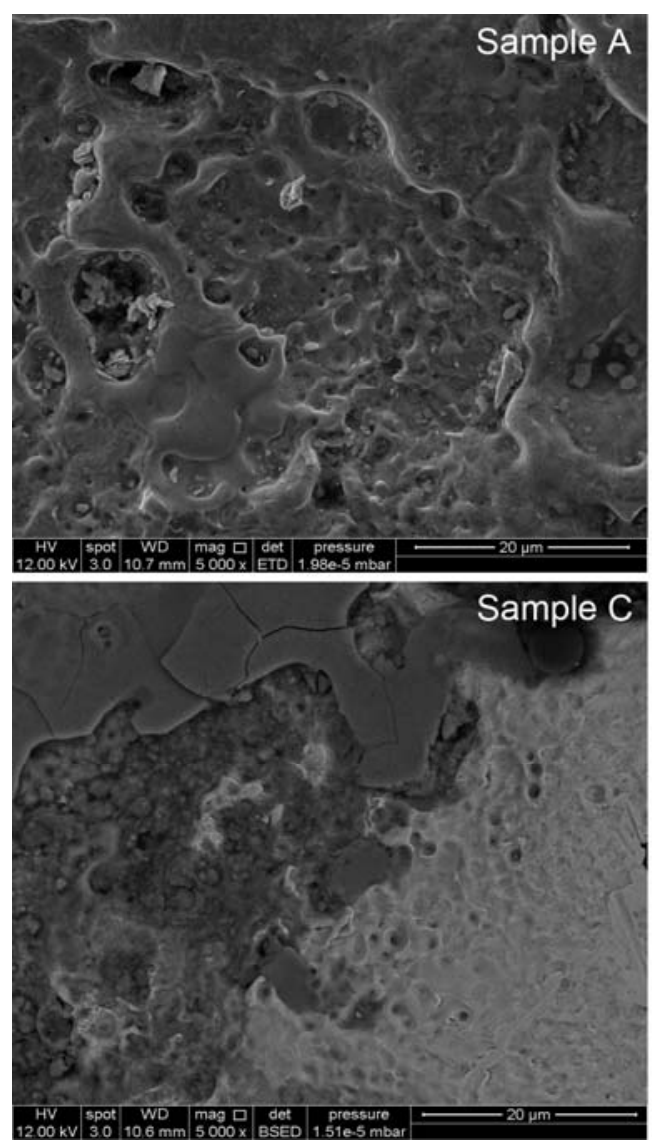

Fig. 2 SEM images taken from surfaces of boronized samples in the same zooming rate. characterization of samples, roughness and wear trace areas were measured with profilometer, hardness was measured with micro-hardness tester, a pin-on-disc configuration was used for wear testing and a tribometer instrument was used.

\section{Result and Discussion}

\subsection{Characterization}

In SEM images taken from 5000x magnified boronized samples using pulsed plasma electrolysis technique, micro structures created as a result of discharges in iron surface can be seen. According to

Table 2 Electrolyte concentrations and application periods of samples.

\begin{tabular}{lll}
\hline Sample & Electrolyte concentration \% & Treatment time (h) \\
\hline A & 10 & 4 \\
B & 15 & 4 \\
C & 10 & 8 \\
D & 15 & 8 \\
\hline
\end{tabular}
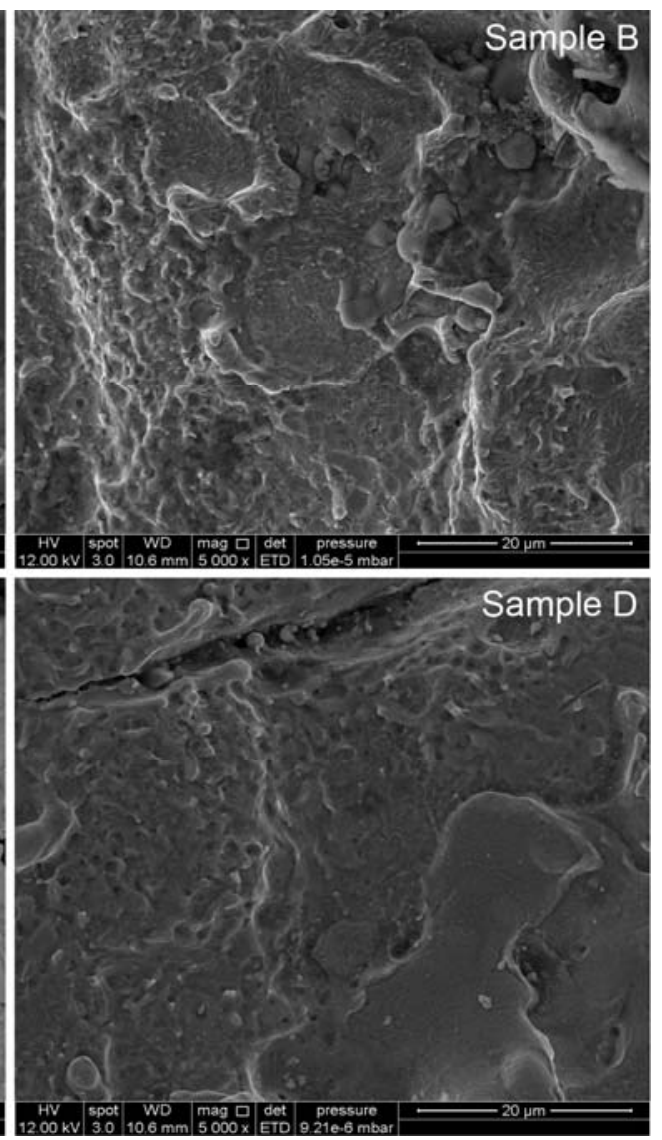


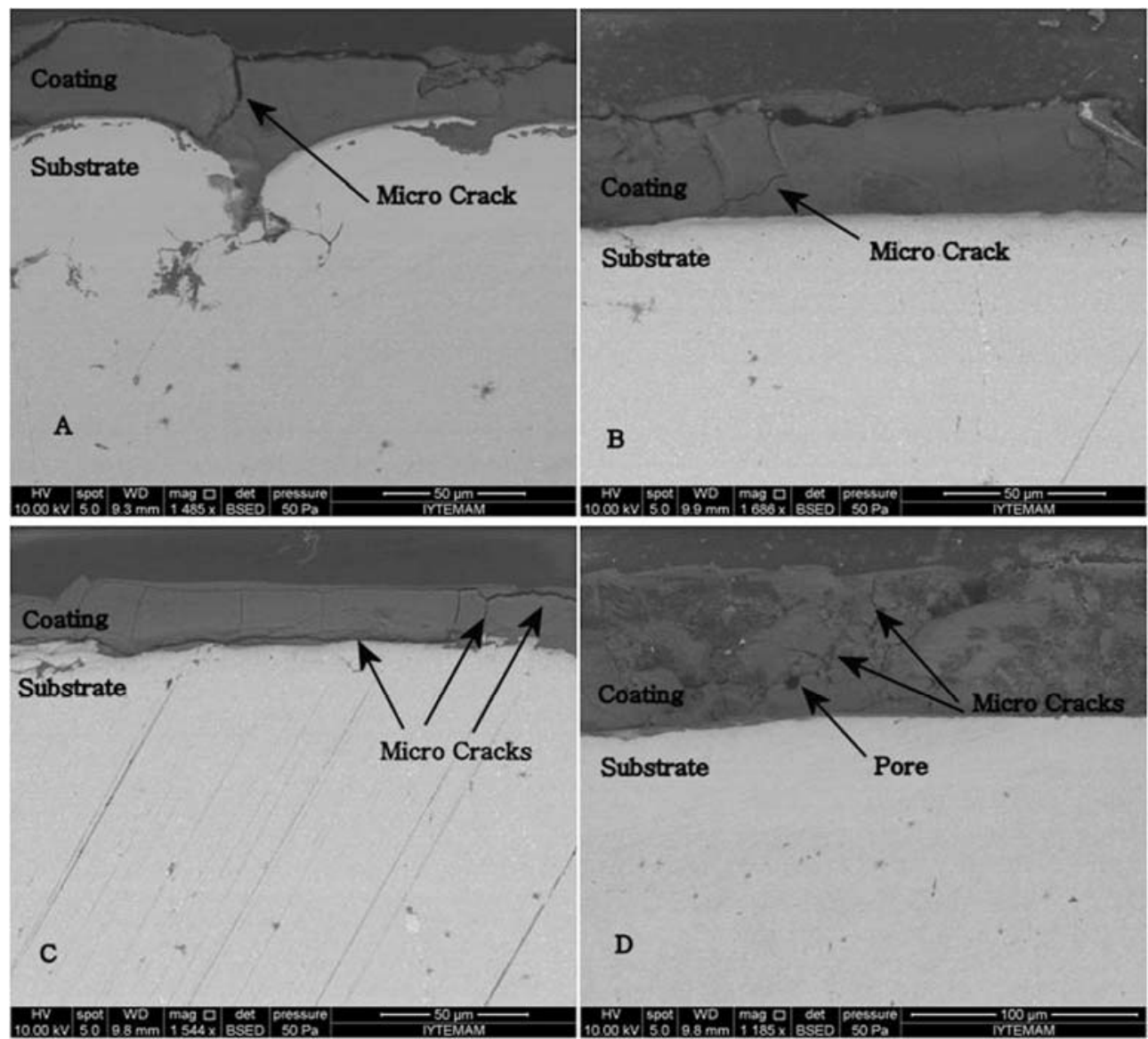

Fig. 3 SEM images taken from cross section of boronized samples.

Table 3 EDAX results.

\begin{tabular}{lllll}
\hline \multirow{2}{*}{ Element } & \multicolumn{4}{c}{ Wt\% } \\
\cline { 2 - 5 } & Sample A & Sample B & Sample C & Sample D \\
\hline B & 10,34 & 11,62 & 16,78 & 18,06 \\
Fe & 81,47 & 82,14 & 77,51 & 75,54 \\
O & 8,19 & 6,24 & 5,71 & 6,40 \\
\hline
\end{tabular}

SEM images, there is no homogenic surface distribution on the surface (Fig. 2). This is a natural consequence of pulsed plasma electrolysis techniques effect on roughness. During the high energy plasma discharging, because of unpredictable ions movement, homogenic coating structure is not observed. Moreover, in SEM images which are given Fig. 2 , it is understandable, especially in the samples B and C, coating formation is observed as the shape of deposited successive lamellar.

When the images of boron layer created on 2365 steel surface, various coating thicknesses depending on the duration of process and concentration variants are observed (Fig. 3). It is thought that, the differences in formation are majorly because of differences in concentration. Crack formations in coating were conspicuously observed in all samples. It is thought that the cracks occur as a result of fracturing during discharging of hard boron layers. Like usual boronizing, $\mathrm{FeB}$ and $\mathrm{Fe}_{2} \mathrm{~B}$ phase were not observed as different layers. Accumulated coating occurred on the surface and penetration was not observed in substrate.

In the performed EDAX analysis, existence of boron in various proportions is identified and these proportions are submitted in Table 3.

\subsection{Tribological Properties}

The variation of coating thickness formed on 2365 steel's surface with pulsed plasma electrolysis technique depending on the duration of process and borax concentration is given in Fig. 4. As it can be understood from the figure, in the same borax 


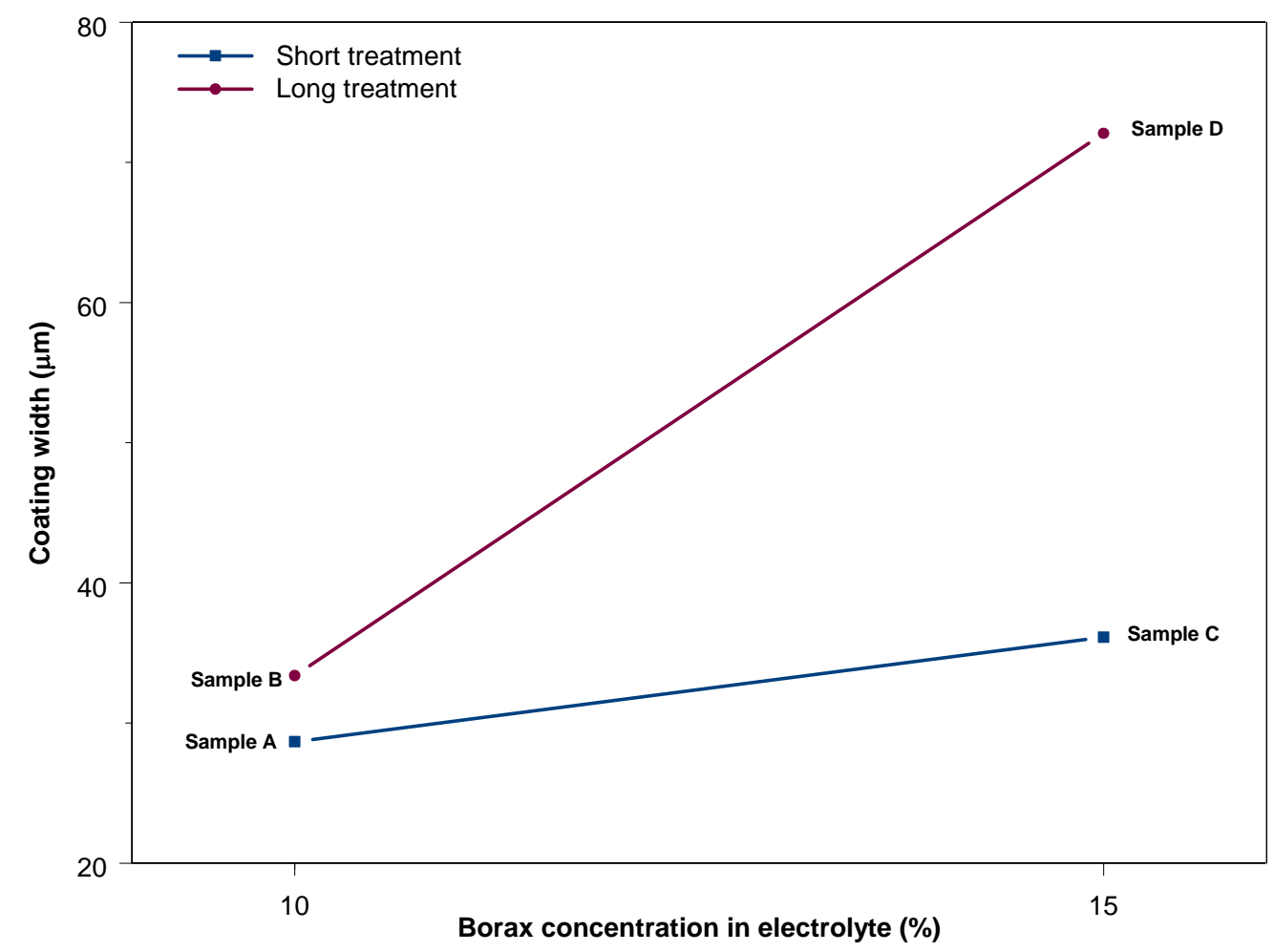

Fig. 4 Distribution chart of coating thickness depending on the duration of the process and borax concentration.

concentration, if you extend the duration of the process, coating thickness is increased, and in the same duration of process, if you increase the borax concentration, again the coating thickness is increased. When the duration of process was extended, there has been much more increase of coating thickness in borax concentration of $10 \%$ than of $15 \%$. The reason is thought to be that if more borax is available, there is much more boron perforating into the surface of the material.

Although a thicker layer is formed in high borax concentration, hardness of these layers is lower than the hardness of layers formed in borax concentration of $10 \%$, as it has been seen in the micro hardness measurements (Fig. 5). In hardness charts of $\mathrm{A}$ and $\mathrm{C}$ samples in borax concentration of $10 \%$, when the duration of process is extended, one can see that the layer thickness doesn't increase at all; however hardness of the newly formed layer increases to some high levels. In B and D samples, when the duration of process is extended, a substantial increase in layer thickness is observed, but in terms of hardness values, this increase falls behind the values in borax concentration of $10 \%$.

Parallel to the findings obtained in hardness tests, a similar result came up in corroding behaviors of samples (Fig. 6). The lowest abrasion value is acquired in electrolyte solution of $10 \%$ in the long process. Abrasion rate decreases 5 times in solution of $10 \%$ base material in the long process. Samples prepared in concentration of $15 \%$ show higher abrasion rates in comparison to other samples of different concentrations. When these findings are combined with the surface hardness, it is thought that the concentration of $10 \%$ is more suitable for 2365 steel considering the abrasion resistance.

Friction coefficient values measured on the surface of the samples during abrasion test are given in Fig. 7. As it is understood from the figures, friction coefficient is lower in boronized samples than the main material. This result contributed to the decrease in abrasion values. As the abrasion process proceeds, 
Technique

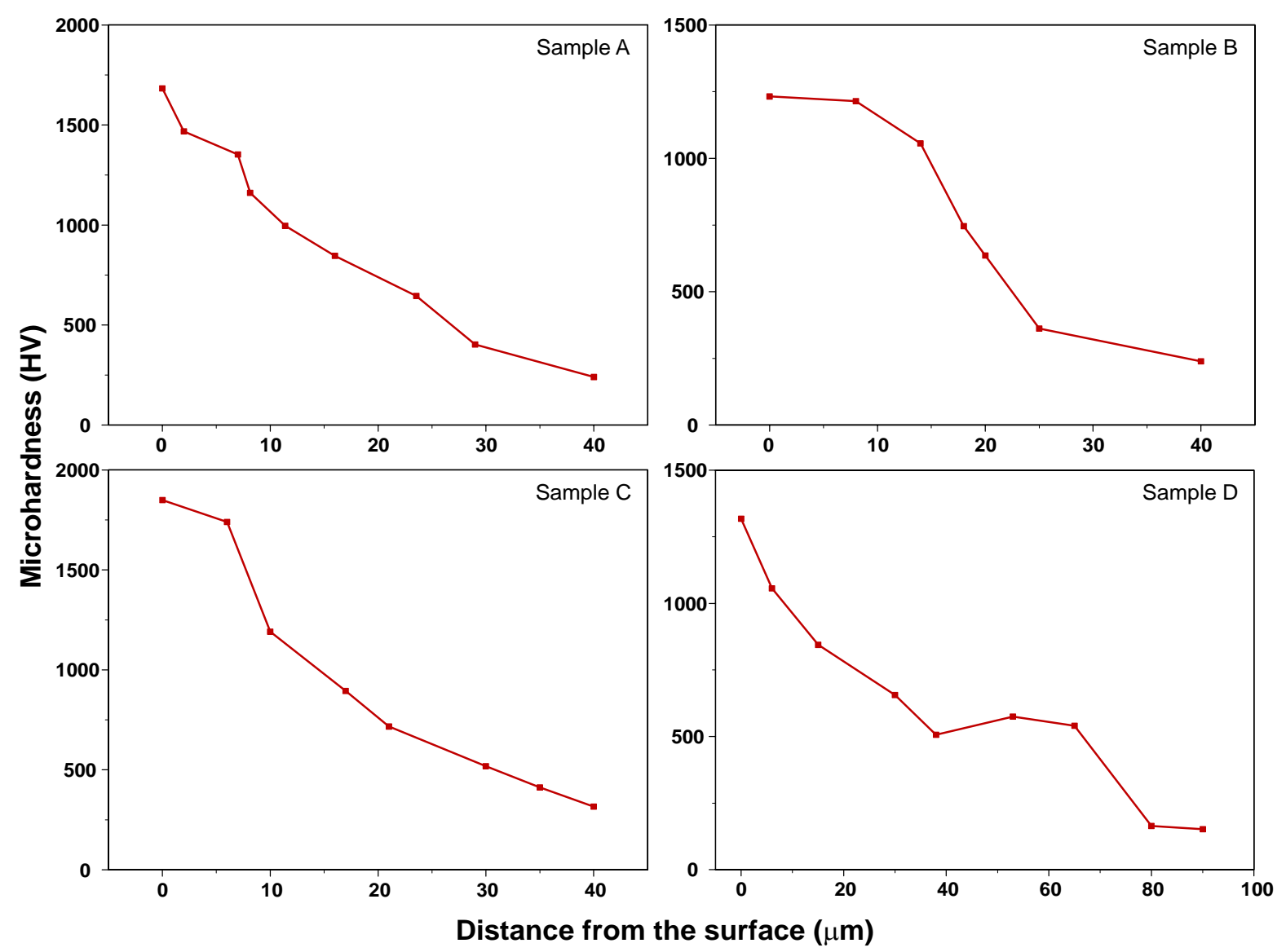

Fig. 5 Micro hardness tests from the cross section.

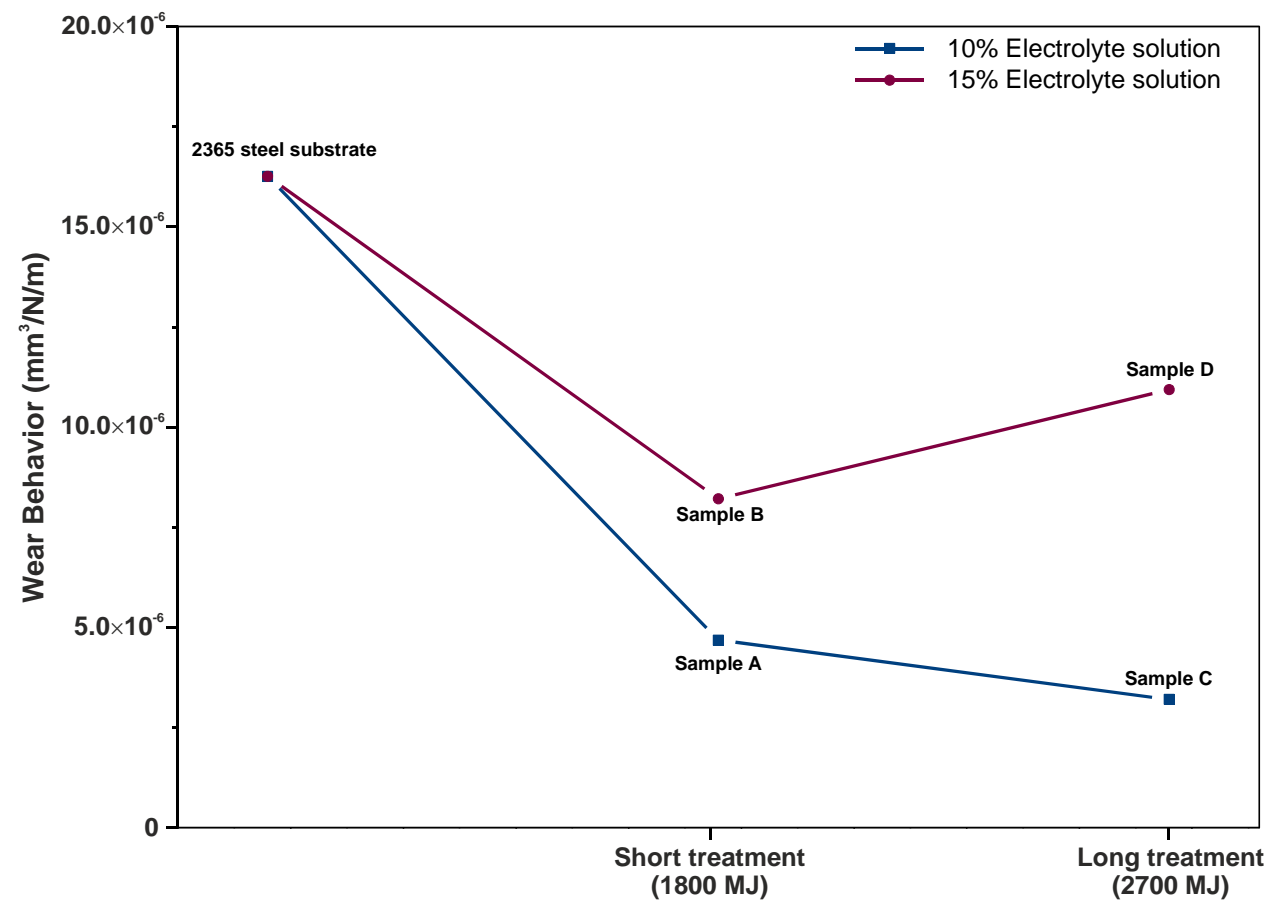

Fig. 6 Abrasion graphic according to concentration and the process. 

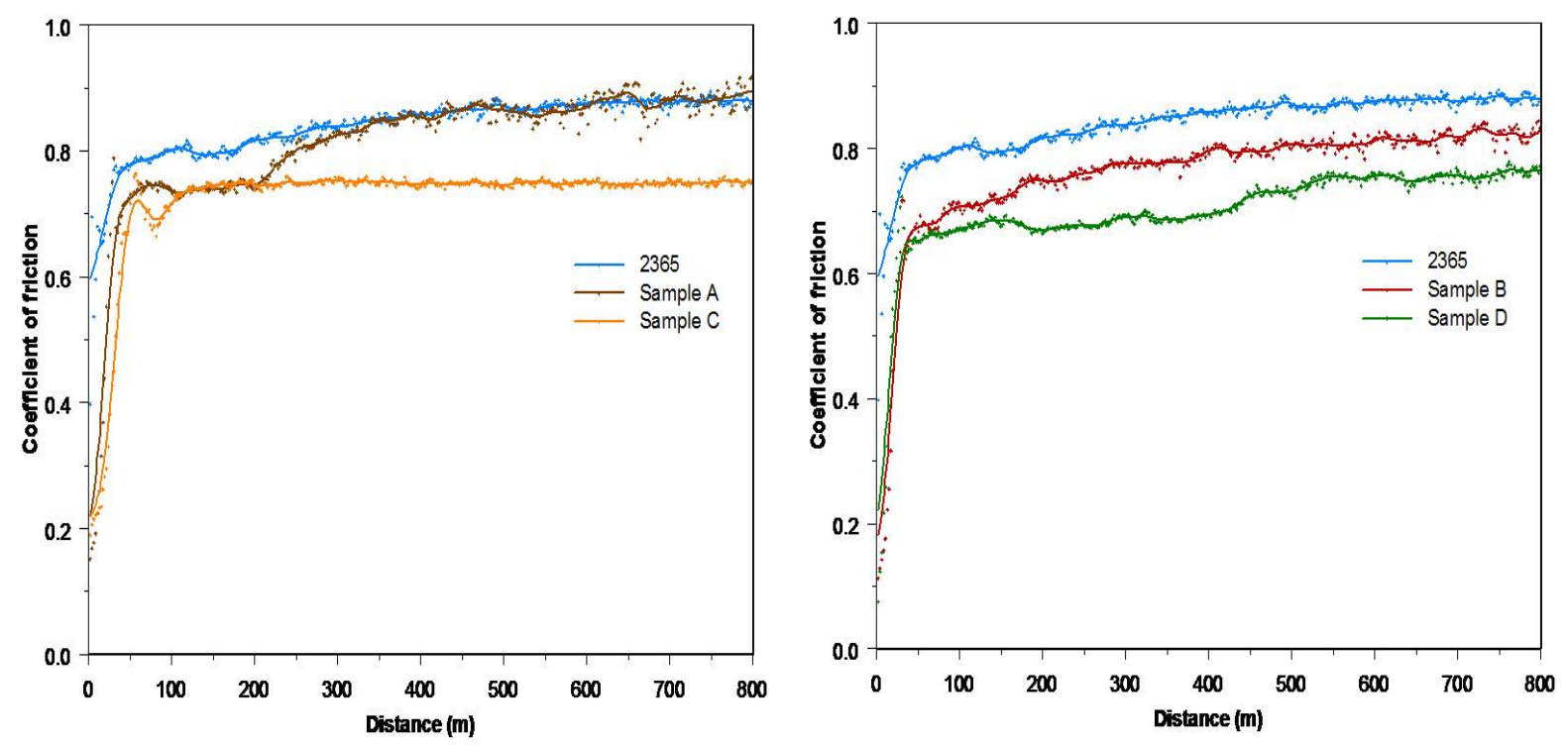

Fig. 7 Friction coefficient measurements from the surface. The samples which were processed short time and long time a) in the electrolyte concentration of $10 \%$, b) in the electrolyte concentration of $15 \%$.

depending on the finished parts, formed surface is slowly lifted and the friction coefficient value approaches to the main material value. The most dense coating was observed in the sample $C$, as shown in SEM images. Moreover, the highest micro hardness was observed in the sample $\mathrm{C}$ as well. Accordingly, during the wear test, the example with the lowest coefficient of surface friction was $\mathrm{C}$.

\section{Conclusions}

In this study, pulsed plasma electrolysis technique is used and 2365 steel is boronized. The characteristics and mechanical features of boronizing are reviewed according to the concentration and processing time variables. According to the findings, the following points are acquired:

(1) 2365 steel is subjected to pulsed plasma electrolysis technique and thus important conditionings in surface hardness and wear behavior are accomplished.

(2) When borax concentration and treatment time raised, it was observed that thickness of coating increased in electrolyte.

(3) It was observed that borax concentration effected the hardness of coating. Coating process with the samples $\mathrm{A}$ and $\mathrm{C}$ which included $10 \%$ borax, acquired the highest level of surface hardness. In those samples which included $15 \%$ borax was observed precipitating in electrolyte and those precipitating affected negatively resistant of electrolyte. According to precipitating in electrolyte, during the discharging, it was observed that plasma's density decreased, as a result of increasing the resistance.

Another important aspect of this study is that electrolyte concentration has a significant effect on process success. It is determined that, electrolyte solution of $10 \%$ gives better results than electrolyte solution of $15 \%$. It is determined that electrolytic solution of $10 \%$ gives better results in terms of hardness and wear values than electrolytic solution of $15 \%$.

It is also determined that the 2365 steel, which is widely used in industry, can be subjected to boronizing economically using the pulsed plasma electrolysis technique without specific atmospheric and temperature requirements so that it makes the hardness of the steel and the wear resistance substantially better.

\section{Acknowledgements}

The work described here was financially supported by Scientific Research Coordinate Unit of Celal Bayar 
University project 2011-040.

\section{References}

[1] Gu, W. -C., Lv, G. -H., Chen, H., Chen, G.-L., Feng, W. -R., Zhang, G. -L., and et al. 2007. "Preparation of Ceramic Coatings on Inner Surface of Steel Tubes Using a Combined Technique of Hot-Dipping and Plasma Electrolytic Oxidation." Journal of Alloys and Compounds 430: 308-312.

[2] Nie, X., Wang, L., Yao, Z. C., Zhang, L., and Cheng, F. 2005. "Sliding Wear Behaviour of Electrolytic Plasma Nitrided Cast Iron and steel." Surface \& Coatings Technology 200: 1745-1750.

[3] Galedari, S. A., and Mousavi Khoei, S. M. 2013. "Effect of Pulse Frequency on Microstructure and Surface Properties of Ck45 Steel Treated by Plasma Electrolysis Method." Journal of Alloys and Compounds 551: 415.

[4] Zeghni, A. E., and Hashmi, M. S. J. 2004. "Comparative Wear Characteristics of Tin and Tic Coated and Uncoated Tool Steel.” Journal of Materials Processing Technology 155-156: 1923-1926.

[5] Yoon, J. H., Jee, Y. K., and Lee, S.Y. 1999. "Plasma Paste Boronizing Treatment of the Stainless Steel AISI 304." Surface and Coatings Technology 112: 71-75.

[6] Wu, J., Xue, W. B., Wang, B., Jin, X. Y., Du, J. C., and Li, Y. L. 2014. "Characterization of Carburized Layer on T8 Steel Fabricated by Cathodic Plasma Electrolysis."
Surface \& Coatings Technology 245: 9-15.

[7] Yan, Z. C., Deng, L. H., and Chen, L. 2013. "Cathodic Plasma Electrolysis in 1-Propanol Solutions for Preparation of Submicron Diamond Particles." Electrochimica Acta 105: 612-7.

[8] Meletis, E. I., Nie, X., Wang, F. L., and Jiang, J. C. 2002. "Electrolytic Plasma Processing for Cleaning and Metal-Coating of Steel Surfaces." Surface and Coatings Technology 150: 246-256.

[9] Yerokhin, A. L., Nie, X., Leyland, A., Matthews, A., and Dowey, S. J. 1999. "Plasma Electrolysis for Surface Engineering." Surface and Coatings Technology 122: 73-93.

[10] Sista, V., Kahvecioglu, O., Eryilmaz, O. L., Erdemir, A., and Timur, S. 2011. "Electrochemical Boriding and Characterization of AISI D2 Tool Steel." Thin Solid Films 520: 1582-8.

[11] Béjar, M. A., and Henríquez, R. 2009. "Surface Hardening of Steel by Plasma-Electrolysis Boronizing." Materials and Design 30: 1726-8.

[12] Balusamy, T., Sankara Narayanan, T. S. N., Ravichandran, K., Park, S., and Lee, M. H. 2013. "Pack Boronizing of AISI H11 Tool Steel: Role of Surface Mechanical Attrition Treatment." Vacuum 97: 36-43.

[13] Anthymidis, K. G., Zinoviadis, P., Roussos, D., and Tsipas, D. N. 2002. "Boriding of nickel in a Fluidized Bed Reactor." Materials Research Bulletin 37: 515-522.

[14] Buderus Edelstahl GmbH. 2010. "Buderus Hot Work Tool Steel 2365 ISO-B.” www.buderus-steel.com. 